Document downloaded from:

http://hdl.handle.net/10251/36084

This paper must be cited as:

Cervelló Royo, RE.; Garrido-Yserte, R.; Segura García Del Río, B. (2012). An urban regeneration model in heritage areas in search of sustainable urban development and internal cohesion. Journal of Cultural Heritage Management and Sustainable Development. 2(1):44-61. doi:10.1108/20441261211223261.

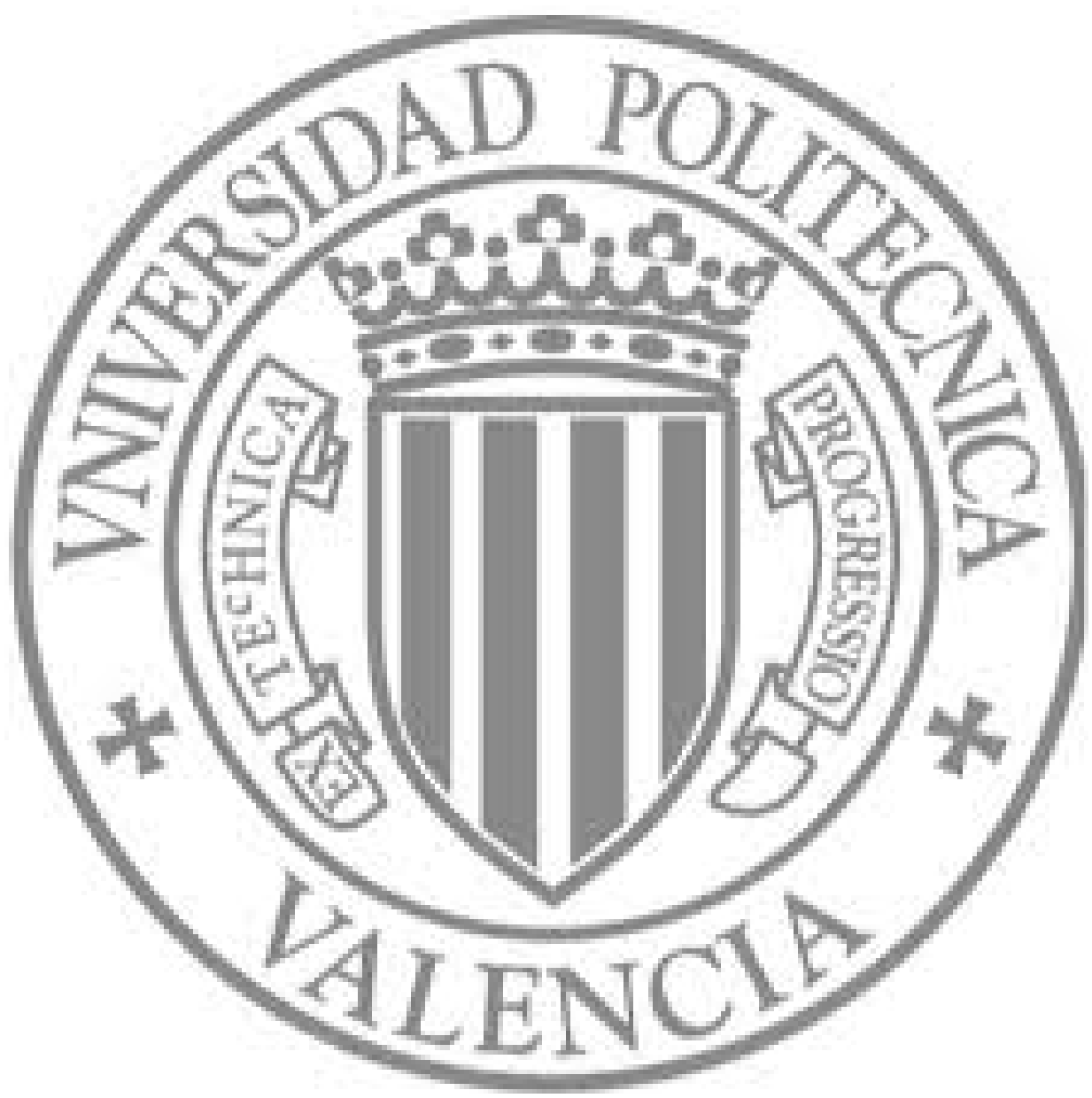

The final publication is available at

http://dx.doi.org/10.1108/20441261211223261

Copyright Emerald 


\title{
A URBAN REGENERATION MODEL IN HERITAGE AREAS IN SEARCH OF SUSTAINABLE URBAN DEVELOPMENT AND INTERNAL COHESION
}

\begin{abstract}
Purpose: This work provides an analysis and an optimization model of the spatial impact for the externalities derived from urban regeneration and rehabilitation of degraded and segregated historic heritage areas.

Design/Methodology/Approach: From the amount invested and state intervention locations, an impact index is put forward. The spatial distribution of these impact indexes in the interventions' area of influence will be the basis for the analysis. Hence, by setting some specific objectives of the decision agent about this distribution homogeneity, and with the aim of avoiding inner segregation and to facilitate the sustainable urban development and cohesion of the neighborhood as a whole, a model which will allow the allocation of the budget available among the different locations fixed a priori is proposed.
\end{abstract}

Findings: By comparing the spatial distributions of impact indexes obtained in both situations, a measure of the urban regeneration and rehabilitation process and its impact can be obtained.

Originality/value: In order to favour the neighborhood internal cohesion and to avoid inner segregation, the model enables to better address priority areas of intervention inside a historic heritage urban area and to better achieve sustainable urbanization by providing a more equitably and efficiently managing of resources. 


\section{INTRODUCTION}

The historic centres of some European cities have undergone a gradual degradation and segregation process which speeded up in the second half of the last century. The causes of degradation have been analyzed in depth by several authors, from both the urban development standpoint and the economic and social perspectives, the latter being the most incidental and fundamental when planning a series of state interventions in a degraded, segregated and marginal historic area.

In Schelling's dynamic models (1971a, 1971b and 1978), an individual's preferences are set regarding the neighborhood area in which he is going to live, in such a way that he will move to or remain in a determined area depending on the neighborhood characteristics. Thus it seems reasonable that an individual will not reach his level of "happiness" in a degraded area. As a consequence of its neglect, a worse deterioration of urban environment will take place, due to both the lack of upkeep and the lack of new investments in public goods and facilities.

Over the last few years, local governments in these cities have implemented schemes for urban regeneration and rehabilitation of those historic areas, particularly in the degraded historic and heritage urban areas closest to the central districts. This has been done not only to improve the urban environment, but to satisfy the demand for housing in cities in an expansion situation, in order to avoid the sprawl effect uncontrolled growth on the outskirts of the city (Glaeser and Shapiro, 2003). In most cases, these rehabilitation plans envisage joint action between the public and private sectors in order to recover these areas, so as to arouse greater residential, commercial, leisure and even tourist interest. Many authors (Van Oers, 2007; Nijkamp 
and Riganti, 2008; Communities and Local Government, 2009) highlight the role of historic built environment in promoting economic and regional growth and development, while others (Avrami et al. 2000, Evans and Shaw, 2001; Greffe, 2004; Evans, 2005; Tweed and Sutherland, 2007; English Heritage, 2009; Pereira Roders and Van Oers, 2011) ascertain how heritage can boost the local and national economy and create employment by increasing tourist and investment appeals and providing leisure, recreation and educational facilities.

The evaluation of urban regeneration programs is a complex issue, given that several aspects are concerned: urban, cultural, social and economic, among others. Furthermore, the beneficial effects like the improvement of the urban environment and living conditions, the upkeep and restoration of facilities that are designated as cultural heritage, the additional urban structures and infrastructures, the restoration of historic built heritage, etc. result in externalities which have an impact on both the economic activity, employment and well-being of the area. These externalities involve all the factors identified as contributing to the overall quality of place, and therefore influencing people's and businesses' choice of location, including diversity, tolerance and safety, environmental quality, aesthetics, amenities, opportunities for recreation, culture and an environment supportive of lifestyle choices (Brown and Meczynski, 2009). Paul Lawless (2004) analyzes and evaluates the results from the ABI (Area Based Initiative) announced in 1998, "New Deal for Communities", in at least five aspects: crime, education, health, worklessness and housing. In fact, the impact regarding this last aspect is potentially quantifiable insofar as housing demand is concerned: the increase in demand of housing in these areas is materialized in more rehabilitation 
work, more promotions of newly built houses, and also in a rise in the market values of property.

The problem arises when the scheme of some of these urban regeneration initiatives do not help to avoid inner segregation and maintenance of less-privileged areas inside an only neighborhood, with the consequent increase of social and economic inequalities.

This study will try to give a solution to this kind of problems. For this purpose, a model is put forward whose main objective is to provide a public investment assignment in search of the most homogeneous impact for the historic neighborhood and the set of possible locations as a whole. Assuming these interventions in cultural heritage and historic residential properties will generate a series of positive externalities, the objective of this study will be to look for the minimum variability situation, in which externalities will equally benefit all the neighborhood areas, thus providing greater cohesion and avoiding internal segregation. With this aim, the model was designed for studying the effect of the public investment assignment among different locations in a determined historic area. A priority intervention area in the city of Valencia (the neighborhood of Velluters) was taken as a reference.

\section{STATE INTERVENTIONS IN URBAN REGENERATION AND THEIR LOCATION: PREVIOUS}

\section{RESEARCH}

There are a large number of studies dealing with state intervention processes in urban regeneration and planning and their effect on the residential areas and neighborhoods. As noted previously, Lawless (2004) studies the Area-based initiatives 
(ABIs) and discusses three major themes that have proved central to the wider urban debate: community engagement, partnership working and the complexity of ABIs. Eden and Tunstall (2006) suggest how to address the ecological aspect within research and practical agendas for urban restoration projects, while several authors (Evans and Shaw, 2001; Stubbs, 2004; Evans, 2005; Jones and Slinn, 2008; Nijkamp and Riganti, 2008; among others) highlight the increasing role of cultural heritage in processes of regeneration and sustainable development of cities and regions. Focusing on urban housing policies, Murie and Rowlands (2008) underline the use of the planning system to deliver different kinds of affordable housing and the resulting styles and densities of urban housing development. Furthermore, Cameron (2003) studies the housing redifferentiation and population displacement effects of urban regeneration.

Gentrification and segregation (Schelling 1969, 1971b, 1972) effects have been widely studied by several authors. De Souza Briggs (1997), Blasius et al, (2007) and Joseph et al, (2007) argue that policy initiatives implemented in order to improve neighborhood environments all arise from the belief that neighborhoods have an important and independent effect on the well-being and life-chances of individuals. From a socioeconomic point of view, two main fields can be differentiated with regards to urban policy initiatives in the improvement of neighborhoods: (a) existence and provision of public goods, amenities and facilities and (b) externalities management (Guellec and Rallen, 1995).

Within the first group are studies that analyze the number and optimum location of public amenities and facilities under the influence of the land market (Sakashita, 1986, Fujita, 1986 and Berliant et al., 2006). For example, these show how households or 
tenants will maximize its utility when the public amenity, which gives a positive service, is located in the centre of the area. Similarly, if the service rendered is negative, it will be located in the outskirts.

With respect to aspects which influence property and real estate, it should be distinguished those which are intimately linked to location from those which are not. The Tiebout model (1956) states that individuals will decide the location of their residence as the place where they can attain the highest level of well-being and security. Royuela et al. (2006) established that the concept of "quality of life" associated with well-being is sustained on the basic supposition that the physical, economic and social setting can influence individuals' economic behavior at the same time as their individual happiness and collective well-being.

Manning (1986) introduces "the interurban household quality of life equilibrium", which states that there is a portion of the population willing to compromise their rent for a higher level of services and better environment. Thus, they increase their utility by means of spatial externalities, which are supposed to be positive.

Thus, when acquiring a property, all attributes and/or location features (e.g., neighborhood characteristics, socio-cultural level, education, safety, etc.) mean spatial externalities which are inherent to the location of the chosen property. Krum (1960) sets an equilibrium model in which, after considering the housing attributes, the value would be explained by the neighborhood homogeneity and the existing level of services. Lynch and Rasmussen (2004) estimate the impact of the neighborhood characteristics on the real estate market, and check how the neighborhood effect on the property market starts to diminish with a distance of 3 to 4 miles. Richardson 
(1977) introduces the "rent externality" component, which reflects the impact of the existing amenities and services, as well as the better quality of the environment in the closest areas to central district. In contrast, Ihlanfeldt (2004) justifies segregation and the existence of "ghettos" due to negative externalities of different nature, such as inadequate housekeeping, citizen insecurity, racial prejudices, etc.

Much of the academic literature deals with spatial and geographical economics and studies spatial externalities. In the case of property and real estate, externalities could be classified in three main groups: physical, social and urban desertification (López García 1992, González-Páramo and Onrubia, 1992). Physical externalities gather all positive and negative aspects that affect the property environment, such as the number of urban amenities and facilities, the presence of green areas, gardens, parks etc. Social externalities gather all positive and negative aspects related to demographic characteristics of a determined area, such as education level, purchasing power or ethnic population. The demographic desertification is an externality linked to the social phenomena of "filtering" and "gentrification" (White, 1984), which are likely to take place in the central neighborhoods of the city.

The effect of externalities on the property are reflected on the well-being or discomfort they have on the individuals. In our case study, spatial externalities obtained from urban regeneration state intervention processes, such as a historical building rehabilitation, are considered to be positive and to imply an increase of the utility of the residents and visitors of the neighborhood.

In summary, academic literature tends to address the optimal location of public goods, amenities and/or facilities, their effects on property and the externalities they arise. 
Frequently, decisions about the location of state interventions in urban areas are motivated by technical, urban or policy factors rather than socio-economic foundations. Therefore, the locations fixed a priori could generally not be changed, whereas budget assignment to each one of the locations could be modified.

Focusing on externalities, they are not always homogeneous and generate segregation and inequality. The purpose of our work is to avoid both segregation and inequality, with the aim of developing and providing a major inner cohesion in the neighborhood. From a measurement point of view, segregation is a way of grouping units, whereas inequality is not. Segregation concerns the allocation of primary units with different levels of characteristics (persons of different races, households of different incomes, etc.) among the subgroups of a larger group, while inequality examines the distribution of a characteristic of the primary units within a given group, with no regard for the membership of those units to subgroups. A common measure is the level of income.

Miles and Song (2009) investigate whether the city of Portland, Oregon has been successful in creating neighborhoods at several economic levels and in avoiding the creation or maintenance of high-poverty areas.

Providing that some of these urban regeneration initiatives have not succeeded in avoiding these inner poverty areas as well as the social and economic inequalities within an only neighborhood; the aim of this work is to study the situation in which the increase of utility and positive externalities would be the most homogeneous and uniform for the neighborhood as a whole, in order to avoid the maintenance of these less-privileged areas and to obtain a more homogeneous and sustainable urban development, which will provide a better internal cohesion. For this purpose, public 
investment is streamed among all intervention locations inside the neighborhood in search of the most homogeneous situation, situation which will be determined by the greater uniformity and, therefore, by the minimum variability of the impact index calculated.

This impact index will depend on the location and amount of public investment. One possibility would be to measure by investment per surrounding (circular) area/surface of influence, assuming that the public service or improvement generates non-saturable assets (e.g. cultural heritage, public places, etc.), for whose consumption no displacement is required and which equally affects all housing comprised in the zone. Thus, and taking the rehabilitation of a historic building front as a example, it increases the utility of all resident and passer-by populations of the area, without producing a saturation in its use or enjoyment, even though this effect diminishes with distance from the intervention location. It should be taken into account that most of the interventions of the studied neighborhood were carried out with the aim of improving public spaces and monuments without a clear bound, or at least explicit in their use or enjoyment.

Thus, the index calculated basically consists of the assignment of a given attribute over the surrounding (circular) area. This follows a similar approach to the law of Clark (1951), which is based on the assumption that urban density decreases with distance from the city centre, and to spatial density indexes introduced in the works by McDonald and McMillen (2000) and McMillen (2004). Derycke (1983) and Bailly (1978) also introduce a mathematical model in which population density is related to the distance to the city centre. 
It should be acknowledged that investments are relatively recent, and that state intervention areas are not isolated. Thus, it could be assumed that interventions in adjacent areas could also influence the neighborhood. In this case study, it will be considered that not only for the distance (Lynch and Rasmussen, 2004), but also for the period of time in which the study was carried out, those effects are considered constants with no influence on the studied area.

\section{PROPOSED MODEL}

As it has been stated before, it is assumed interventions in cultural heritage and historic residential properties will generate a series of positive externalities. Therefore, the conception of the proposed model is to look for the most homogeneous situation in which externalities will equally benefit all the neighborhood areas, thus providing a better sustainable urban development and cohesion and avoiding internal segregation. For this purpose and to measure these effects, an impact index was created.

In order to calculate the impact index, it will be assumed a discrete space with $N$ possible points of location of interventions in a particular area of the city, and $M$ locations or sub-areas (zones) of influence, as well as an (I) vector, $N$-dimensional, whose $I_{j}$ elements are the economic value of the investment made at the point of intervention $j$.

This vector $(I)$ will generate an impact index $Y_{i}$ at each location or sub-area (zone) of influence: $(Y)$ will be used to designate the $M$-dimensional vector with all the impact indexes. In principle, the main target will be to get the most possible homogeneous distribution of the positive effects of externalities derived from the state interventions 
processes. This will allow the most uniform effect on the utility of individuals and a greater cohesion on the neighborhood development, thus avoiding segregation and differentiation in internal sub-areas (zones). According to the homogeneity principle and in search of spatial equity, one possible way of measuring this territorial equity and comparing different situations could be carried out through study and observation of the investment assignment among different locations. In this way, it is possible to check the variability of its effect in both scenarios ("current situation" and "minimum variability situation").

Assuming that the intervention effects are distributed in surrounding (circular) areas throughout the neighborhood (as they are assumed to generate public good/amenities non-saturable which require no movement in order to enjoy them), the impact index could be represented as

$$
Y_{i}=\frac{I_{j}}{\pi d_{i j}{ }^{2}} \quad j=1, \ldots, N \quad i=1, \ldots, M
$$

where

$Y_{i}=$ is the value of the impact index of the investment for the location $i$

$I_{j}$ is the investment value made in the intervention located at $j$ (measured in $€$ )

$\pi d_{i j}{ }^{2}=$ is the sub-area (zone) of influence (measured in surface unit) of the intervention located at $j$ upon the $i$ location, with a radius of $d_{i j}$

$d_{i j}=$ is the distance between location $i$ and location $j$ being $j$ a location where an intervention has taken place, with $d_{i j} \neq 0 \quad \forall i j$, with the aim of avoiding null distances. 
$\pi=$ constant $(3.14159 \ldots)$

Considering that the effects of all the neighborhood improvements in a location $i$ for each one of the $N$ locations of the interventions are aggregated, and as it has been previously commented, the effects of adjacent areas are constant.

$Y_{\text {iagregated }}=\sum_{j=1}^{N} \frac{I_{j}}{\pi d_{i j}{ }^{2}}$

It has been set out as main target the impact index vector to be as homogeneous as possible. In other words, to get its minimum variability, which can be measured by the variance of the elements of the vector $\left(Y_{\text {agregated }}\right)$ whose average index is $\bar{Y}=\frac{1}{M} \sum_{i=1}^{M} Y_{\text {iagregated }}$

$V\left(Y_{\text {agregated }}\right)=\frac{1}{M} \sum_{i=1}^{M}\left(Y_{\text {agregated }}-\bar{Y}^{2}\right.$

Thus, the model enabling us to find the distribution of the budget assigned to the interventions which provides the minimum variability to the impact vector and, therefore, its greater uniformity would be

Minimize $=\frac{1}{M} \sum_{i=1}^{M}\left(Y_{\text {agrrgated }}-\bar{Y}\right)^{2}$

subject to

$\sum_{j=1}^{N} I_{j} \leq B$

$\bar{Y} \geq k$

$I_{j} \geq 0$

$\forall j=1, \ldots, N$ 
In this equation, $B$ is the total budget assigned to the intervention and $k$ is a minimum value of average impact of the investment. In this case, $k$ corresponds to the average index obtained $\bar{Y}$ with the assignment of the investment in the "current situation", and could be considered a measure of the well-being obtained in this situation. It will also represent a threshold/line for the "minimum variability situation". Our aim is for the average impact index obtained in this situation of major uniformity and cohesion to be equal or even higher than that for the "current situation". Thus, for the same budget $B$ and with this threshold/line $k$, it could be guaranteed that the average impact of the positive externalities for the neighborhood as a whole in the "minimum variability situation" would be, at least, equal to the "current situation", which in our area of study (Velluters) will have a value of $38,284,176.10 €$ and $126.24 € /$ surface units respectively.

Therefore, by comparison of the distribution and the average impact of the positive externalities between both situations, the model will enable to better address priority areas of intervention and to better achieve sustainable urbanization and internal cohesion by providing a more equitably and efficiently managing of resources inside a cultural heritage and historic area.

\section{CASE Study: Velluters neighborhood (VAlencia)}

The city of Valencia is the third largest city in Spain with a population of 814,208 people in 2009 (INE, 2009),). During the last few years it has undergone a wide expansion, development and growth process that led to a series of urban interventions aimed at recovering the historically traditional and most degraded areas, such as the Velluters neighborhood. The present Velluters neighborhood (also known as the "Barrio del Pilar") is located in District 1 of the city of Valencia (See Figure 1), known as Ciutat Vella. Although its origins are ambiguous, it used to be a craftsmen's quarter with a simple urban layout located between the western limits of the Moslem and 
Christian city walls, at present surrounded by the other Ciutat Vella neighborhoods

(Figure 2).

Figure 1. Location of the "Velluters/El Pilar" neighborhood in the city of Valencia

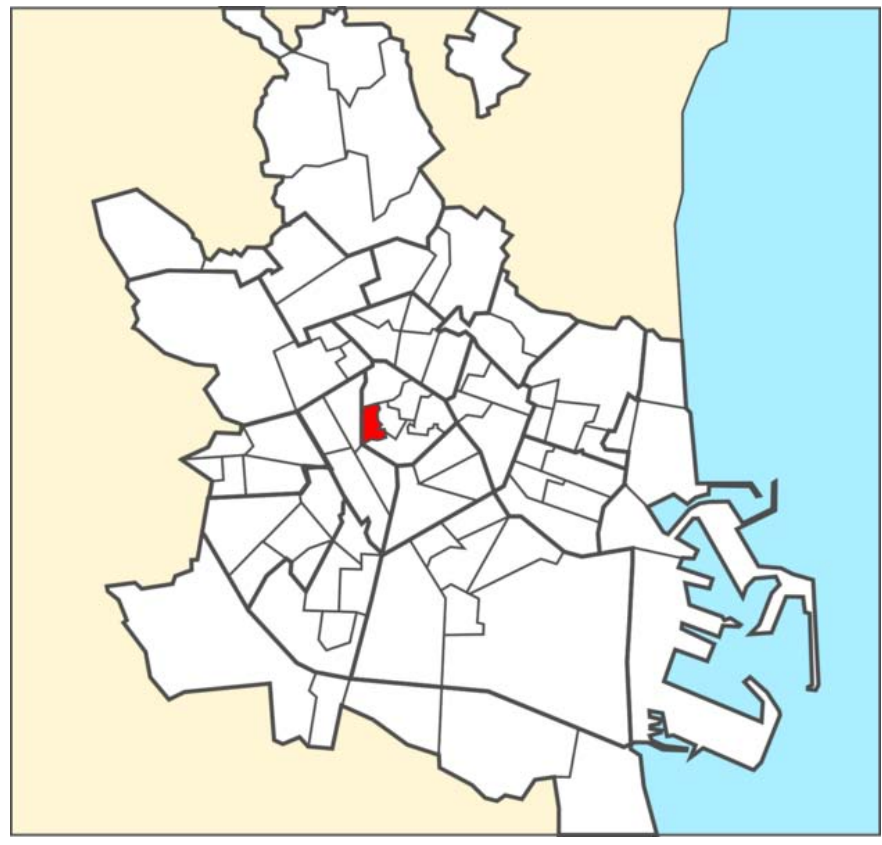

Source: Valencia Clty Council Statistics Office

Figure 2. Map of the "Velluters/El Pilar" neighborhood
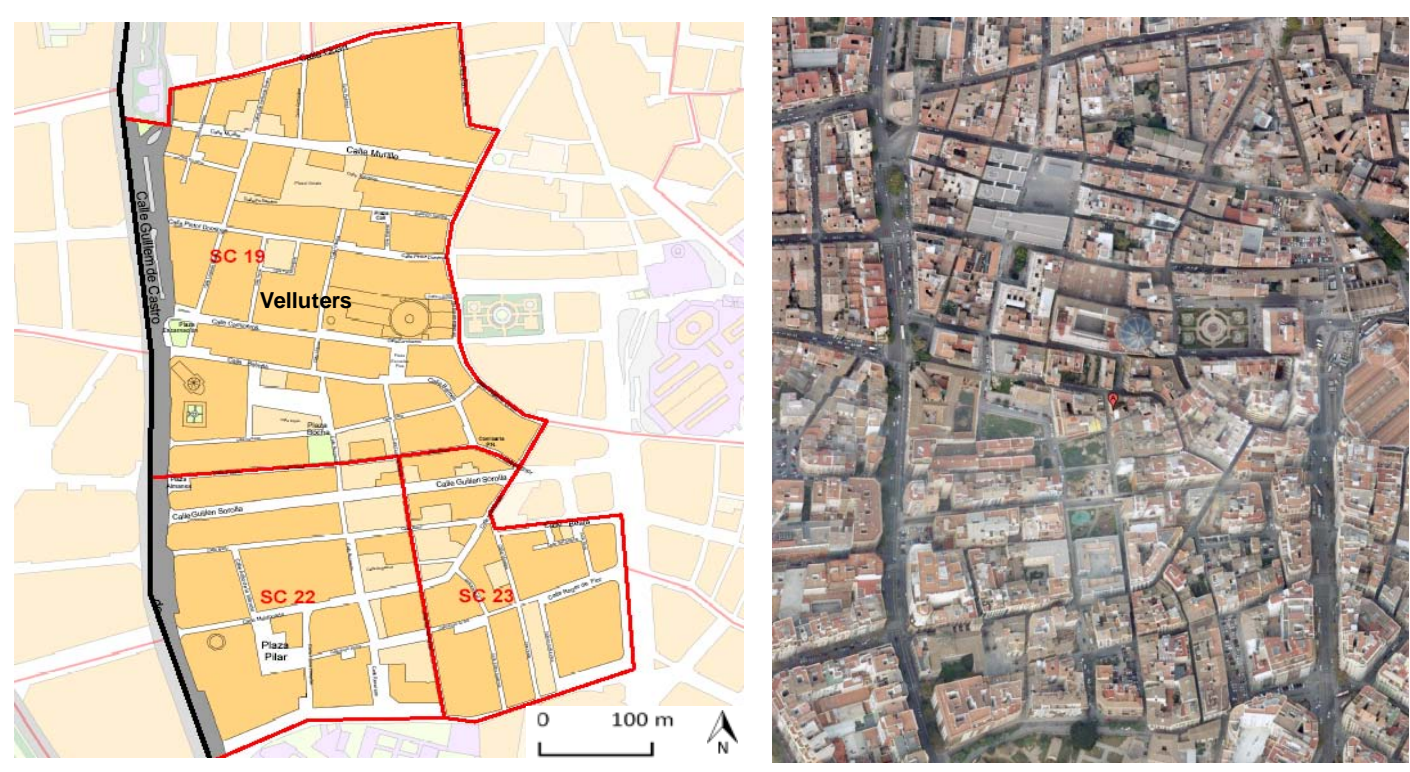

Source: Valencia Clty Council Statistics Office

In the 19th century, historic events took place that affected the fabric of the neighborhood to a greater or lesser extent. The neighborhood began to fall into decay 
and be largely overlooked. Provoking its segregation with respect to the rest of the Ciutat Vella neighborhoods, it turned to be one of the most underprivileged areas of the historic centre with a marginalized and ageing resident population (See Figure 3).

Figure 3. Velluters neighborhood degraded areas

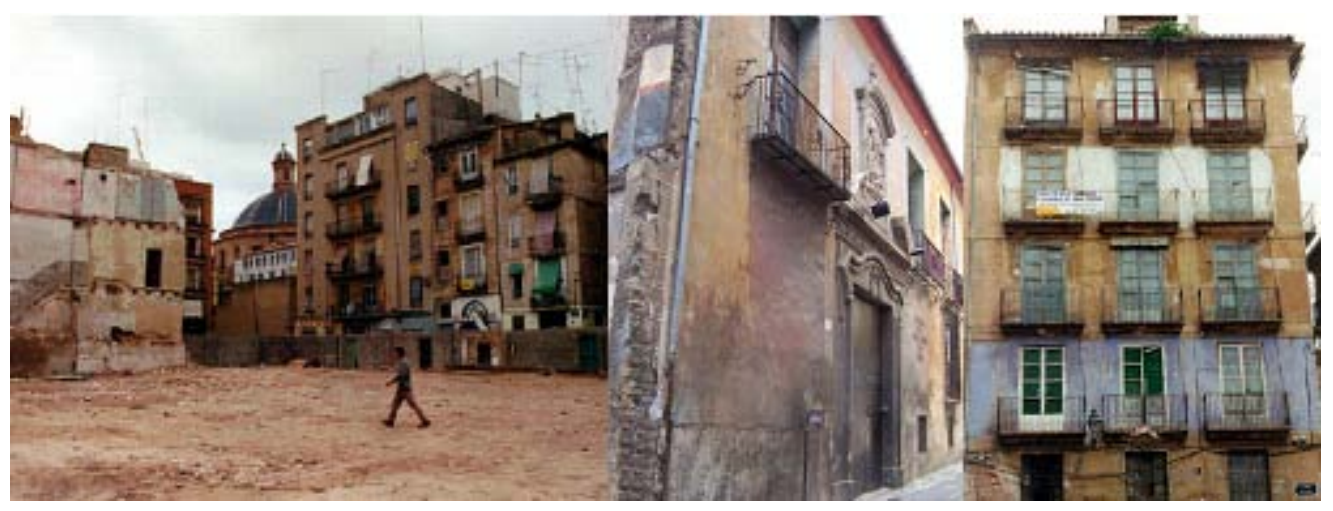

Source: Riva Office and own elaboration

In view of this evident degradation of the historic centre, the city council and the regional government signed an agreement of joint intervention in order to develop the RIVA Plan (Plan de Rehabilitación Integral de Valencia). This is a plan for the comprehensive rehabilitation of Valencia, in which the Velluters neighborhood was one of the main areas of intervention (See Figure 4).

Figure 4. Works done in the Velluters neighborhood areas of intervention

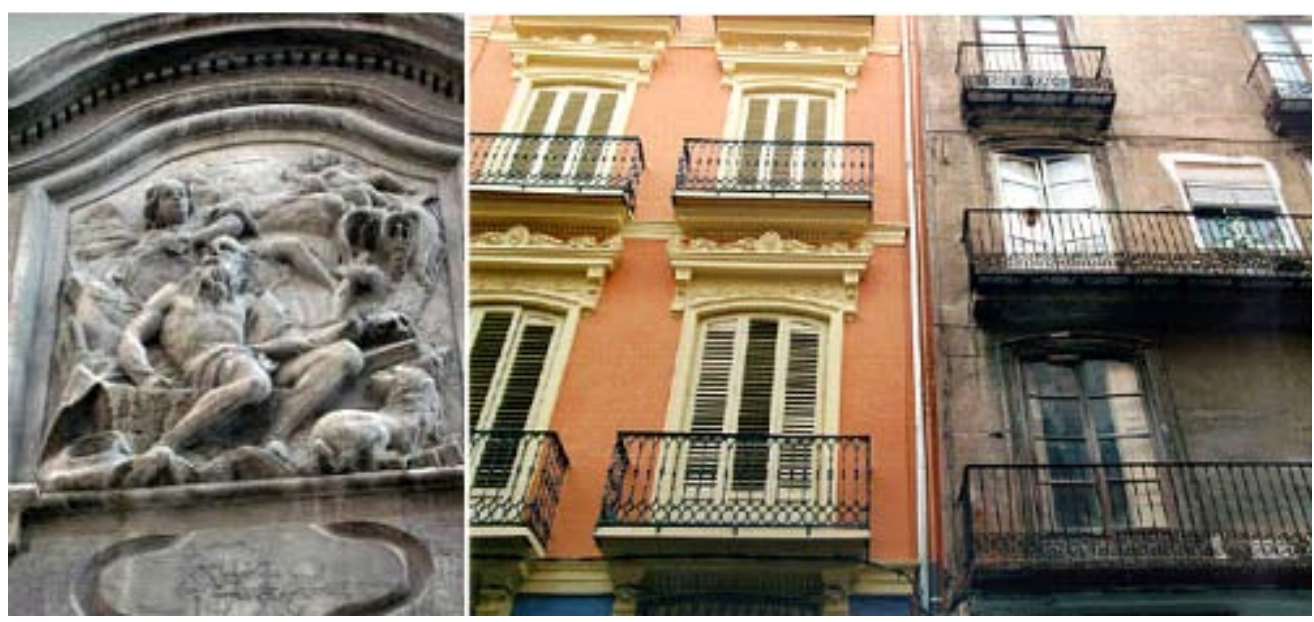




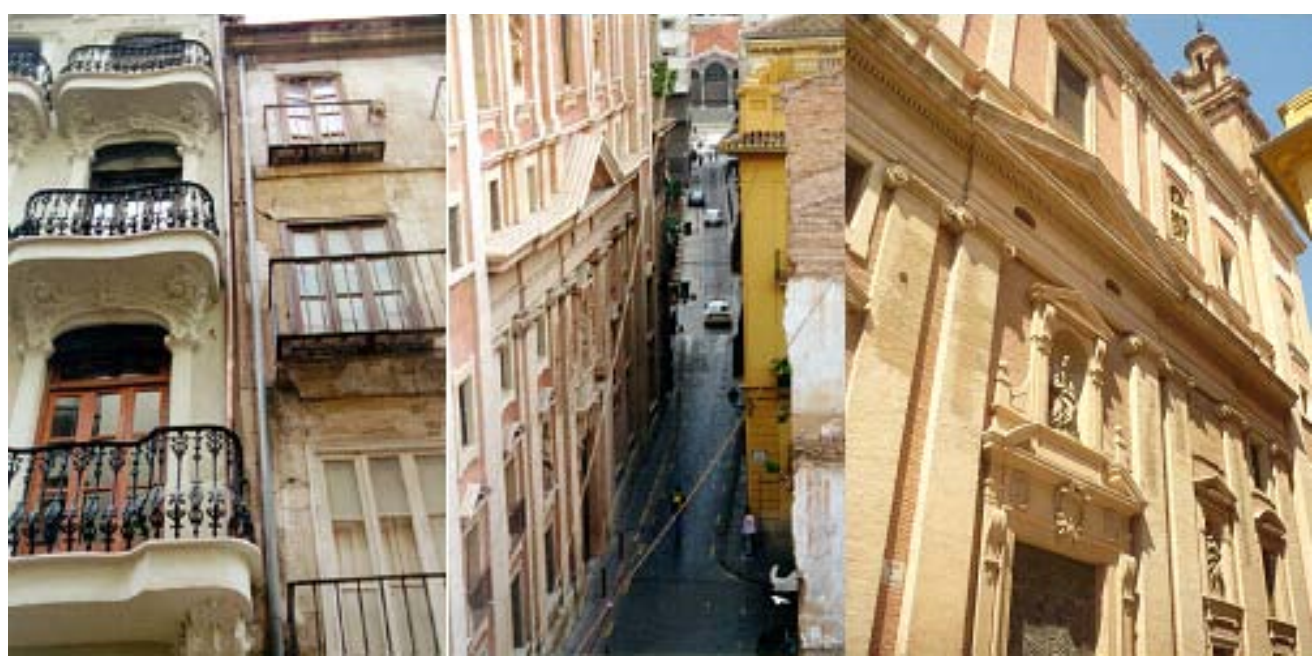

Source: Riva Office and own elaboration

The main objectives of the plan are as follows:

-To revitalize the historic centre.

-To retain the population inhabiting the historic centre and to attract new residents.

-To improve the quality of life of residents through the quality of services.

-To create social, cultural and educational services, focused on the most degraded and marginal areas of the city.

-To improve the integration of the historic centre in the city, as differences in amenities and facilities provision are equilibrated between the historic centre and other more recently created areas

-To give an incentive to private initiative in order to rehabilitate the residential heritage.

-To give an incentive to build new buildings.

At present, the general atmosphere of the neighborhood is different; it is starting to be chosen as a centre for activities for certain businesses and for public and private institutions. The main improvements in the Velluters neighborhood have taken place in the urban sphere. However, there is a series of indicators which signal a general improvement in the quality and environment of the neighborhood: 
-An increase in the population from 3,861 (1996) to 4,067 (2009), reaching $15.69 \%$ of the entire population of Ciutat Vella (District 1) and 3.18\% of the entire population of Valencia city in 2009.

-The change to the service economy and in the activity of the neighborhood, which in 2009 comprised $62.3 \%$ by commerce and services, $29.8 \%$ by professionals and artists, and $8 \%$ by industrial activities.

-An increase of 2,045 in new buildings since the 19th century, as well as an increase in selling and rental prices.

\section{EMPIRIC DESIGN: SAMPLE AND RESULTS}

The sample of interventions taken on the Velluters neighborhood from 1998 to 2006 can be split into two main groups: First, measures on cultural heritage and service amenities (public goods) and second, measures on historic property for residential use (private property) connected with subsidies received by private people for private rehabilitation (See Table 1).

Table 1. Interventions taken in the Velluters neighborhood

\begin{tabular}{ccc}
\hline \multicolumn{2}{c}{ State Interventions in the Velluters neighborhood } & \\
\hline $\begin{array}{c}\text { Measures on cultural } \\
\text { heritage, amenities and } \\
\text { facilities } \\
\text { ( public goods) }\end{array}$ & $\begin{array}{c}\text { Measures on historic } \\
\text { residential buildings } \\
\text { (private property) }\end{array}$ & Total Investment \\
\hline 23 interventions & 10 interventions & 33 interventions \\
$32,224,763.81 €$ & $6,059,412.31 €$ & $38,284,176.10 €$ \\
\hline
\end{tabular}

N.B.: This table shows the distribution of state interventions in Velluters. There are a total number of 23 public interventions and 10 interventions on housing. All action was undertaken in the city of Valencia from 1998 to 2003. 
To make the space in the neighborhood discrete, its total surface area was divided into a grid of roughly block-sized squares (locations) of 50x50m. Thus the west-east axis was divided into 9 units and the north-south into 19, with 171 squares in all. These covered the total surface area and allowed to measure both the investment and the impact index in the centre of each concrete block-sized square. The 33 original locations of the interventions are kept, since this is a decision already passed by municipal authorities. Thus, the vector $(I)=\left[I_{1}, \ldots, I_{33}\right]^{T}$ has a dimension of $N=33$ and the vector $(Y)\left(Y_{\text {agregated }}\right)=\left[Y_{1}, \ldots, I_{171}\right]^{T}$ has a dimension of $M=171$.

It will be supposed that effects inside a concrete block-sized square are homogeneous and, therefore, will equally affect the whole concrete block-sized square area. With the initial investment distribution, a "current" distribution for the impact index generated was obtained, resulting in an average initial value. A more homogeneous distribution ("minimum variability") could be obtained, without the result as a whole being worse than the initial one ("current situation"). This result will be measured by the average index value, which should be higher than that obtained for the "current situation" (126.24€/surface unit).

If the 33 investments are located and represented on a plane by means of map symbols (circles) which are proportional to the corresponding investment, a specific weight could be assigned to them, as demonstrated in Figures 5 and 6 . Figure 5 shows the "current situation" and Figure 6 shows the investment distribution for the "minimum variability situation", whose average impact index is $126.77 € /$ surface unit (higher than the $126.24 € /$ surface unit obtained for the "current situation") with the same budget $B$ and the same locations $j$. 
With regard to the distribution of impact vector $(Y)\left(Y_{\text {agregated }}\right)$, major differences can also be seen (Figure 7). For the "current situation", the highest values of the impact indexes are concentrated in the blocks close to the interventions executed, with considerable differences between the closest squares as opposed to those that would have been provided by the "minimum variability situation", where the distribution of the index is substantially more uniform. Lastly, Figure 8 shows the relative difference existing between the distribution index for the "current situation" and for the "minimum variability situation". For this minimum variability situation, the distribution of the index is substantially more homogeneous, favouring the zones which hard benefit from the current situation.

This formulation is obviously not the only one possible. The model could be extended in two directions. Firstly, conditional restrictions requiring minimum public investments in certain zones could be incorporated, or for the impact index in certain zones to reach certain values in order to attain particular objectives set by public authorities in the intervention process.

Alternatively, the model could also be extended to obtain the endogenous location of the intervention zones, simply by extending vector $(I)$ to all the squares in the neighborhood instead of only 33. In this case, however, a different impact index should be used, as some of $d_{i j}$ would logically be null. Nevertheless, endogenous location does not make much sense for the type of interventions which has been analyzed, as the initial situation of the neighborhood will be what conditions the location. In other types of services (education, health or emergencies), endogenous location could make more sense. 
Figure 5. Density of the investment: current situation

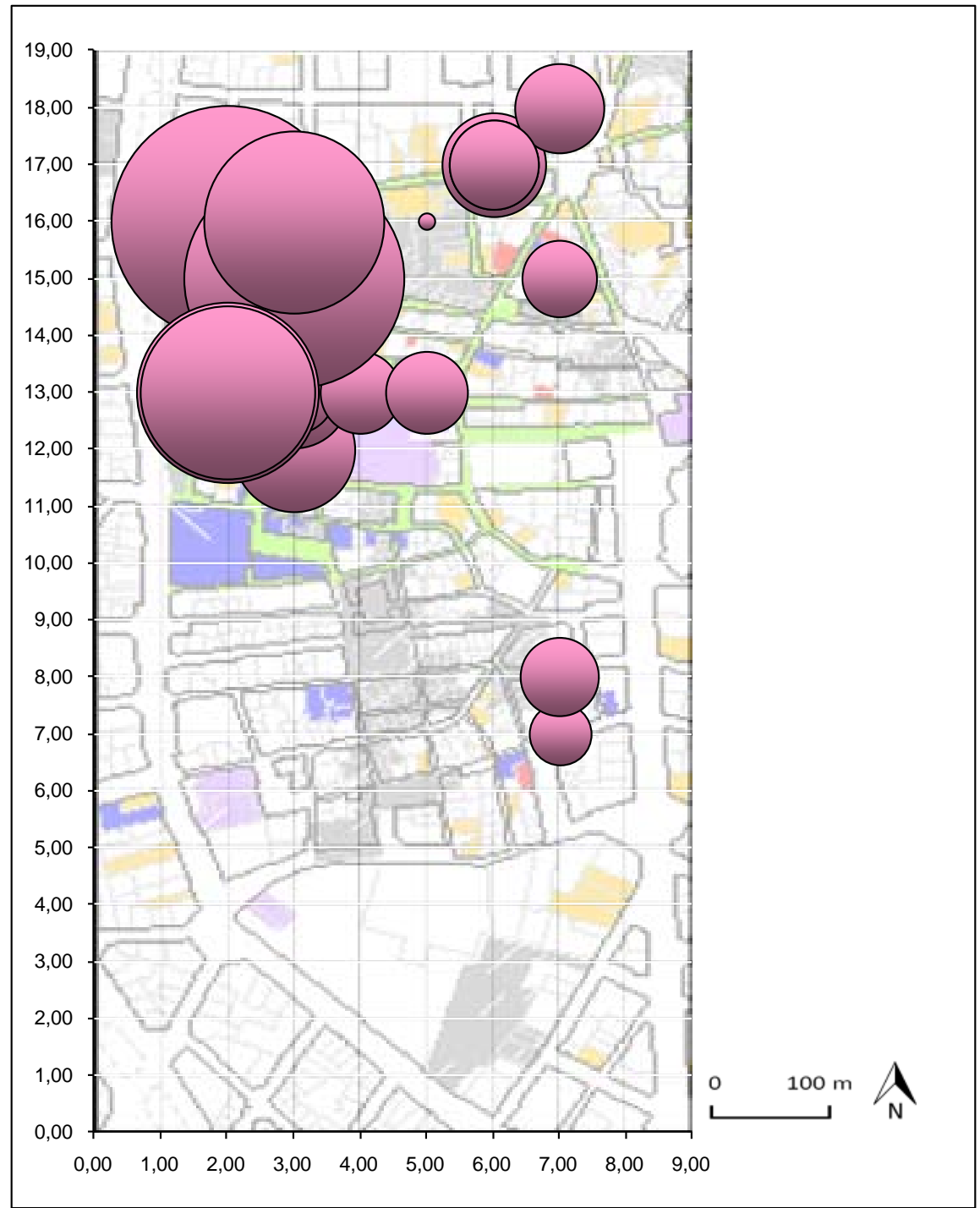

Source: Authors' elaboration
Figure 6. Density of the investment: minimum variability situation

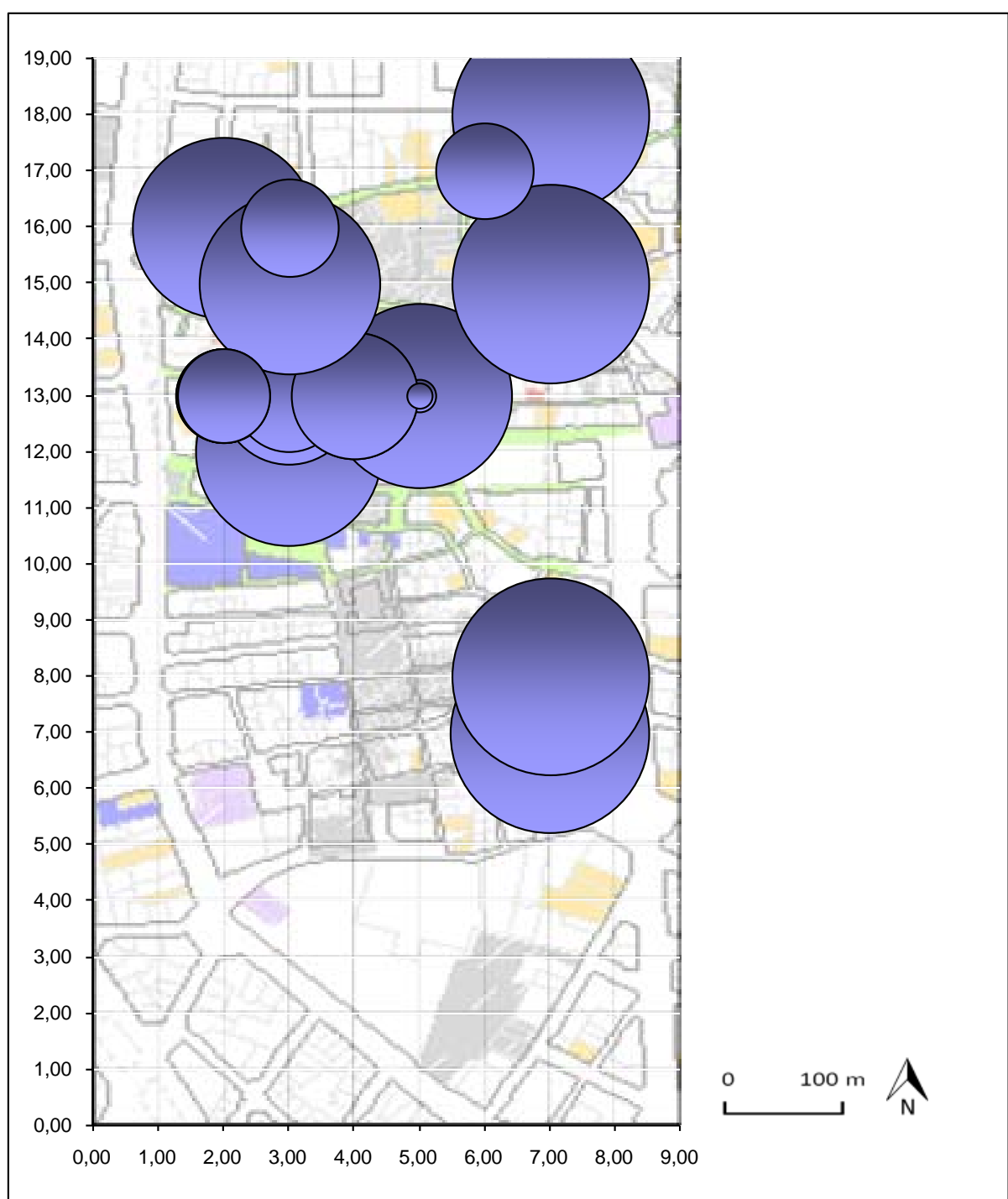

Source: Authors' elaboration 
Figure 7. State intervention index. Post-intervention analysis: current situation vs. minimum variability situation.
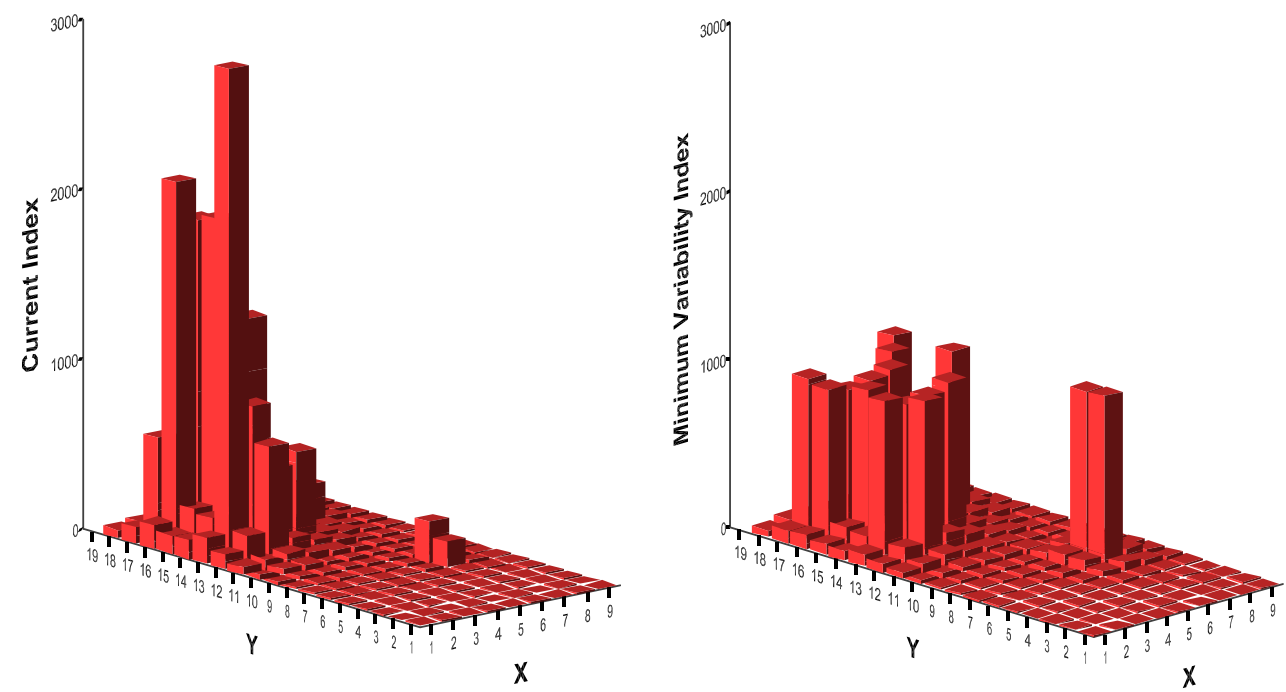

Source: Authors' elaboration

Figure 8. Variation of the state intervention index between the current situation and the minimum variability situation.

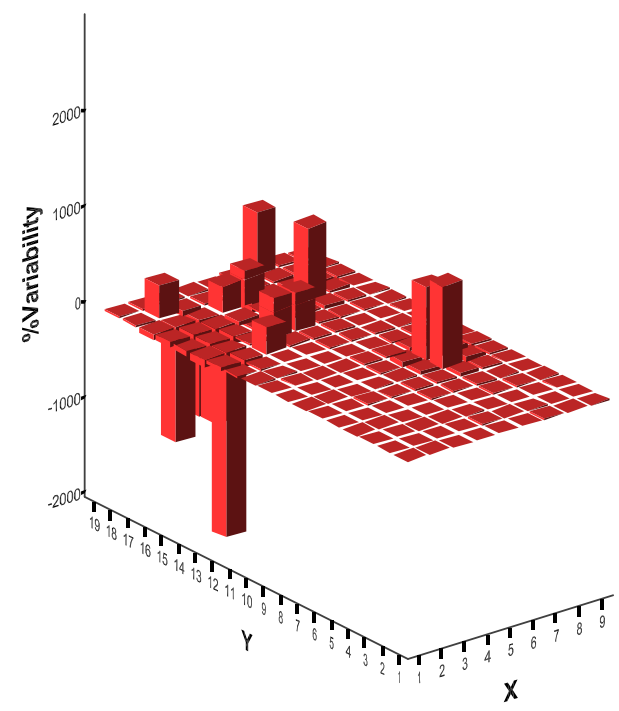

Source: Authors' elaboration

\section{CONCLUSIONS}

This article presents a model whose main target is greater homogeneity for the positive effects derived from the externalities, with the aim of both better sustainable urban development and internal cohesion in the neighborhood as a whole, by means 
of a redistribution in the assignment of public investments among the intervention locations. This target is obviously not the only one possible; even multiple objectives could be considered. As it has been also summarized through the model estimations, some constraints about the nature of the intervention or their expected effects at determined locations could also be introduced.

The model allows for comparing different situations and, therefore, it can be concluded that structures more sensitive to the environment and with greater flexibility are required. This could be useful when setting strategies in the field of cultural and urban planning.

The results obtained show that (i) for the same number of locations the structure obtained for the investment vector $(I)$ is very different to the initial one; (ii) exceeding the minimum value established, the distribution obtained for the impact vector $(Y)\left(Y_{\text {agregated }}\right)$ in the "minimum variability situation" proves far more homogeneous and provides a higher average impact index; (iii) this more homogenous distribution favours the most segregated and less benefited sub-areas (zones) in the "current situation", providing greater internal cohesion and better sustainable urban development for the neighborhood as a whole, with subsequent improvement in the level of well-being for the whole neighborhood and, thus, of quality of life and utility of individuals. This presupposes that all changes arising and endowments stemming from the processes are positive. On the other hand, the model can be extended either by introducing conditional restrictions or by considering endogenous locations.

The paper offers interesting implications for local government and municipal authorities; regarding the urban management, regeneration and rehabilitation 
standpoint, the model enables to better address priority areas of intervention inside a

whole neighborhood and to better achieve sustainable urbanization when carrying out an urban regeneration and rehabilitation process by providing them and their partners (public and private sector) a more equitably and efficiently managing of resources in cultural heritage and historic residential urban areas.

\section{REFERENCES}

Avrami, E., de la Torre, M., Mason, R. (eds.), 2000, The Values and Heritage Conservation: Research Report, Los Angeles: Getty Conservation Institute, from www.getty.edu/conservation/resources/

Bailly, A.S. (1978), La organización urbana. Teorías y modelos, (IEAL Nuevo Urbanismo/28), Madrid

Berliant, M., Peng, S.K. and Wang P. (2006), "Welfare analysis of the number and locations of local public facilities", Regional Science and Urban Economics, Vol.36, pp.207-226.

Blasius, J., Friedrichs, J. and Galster, G. (2007), "Introduction: Frontiers of quantifying neighbourhood effects", Housing Studies, Vol. 22, No.5, pp. 627-636.

Brown, J., Meczynski, M. (2009), “Complexcities': Locational Choices of Creative Knowledge Workers, in Built Environment, Can We Plan the Creative Knowledge City?", vol.35 (2) (Guest eds. Caroline Chapain, Chris Collinge, Peter Lee and Sako Musterd), in Alexandrine Press ed. Peter Hall, David Banister, pp. 238 - 252.

Cameron, S. (2003), "Gentrification, housing redifferentiation and urban regeneration: going for growth in Newcastle upon Type", Urban Studies, Vol.40, pp. 2367-2382.

Clark, C. (1951), The conditions of economic progress (McMillan), London

Communities and Local Government (2009), "Draft Planning Policy Statement 15: Planning for the Historic Environment", Communities and Local Government Publications, London, July available http://communities.gov.uk/documents/planningandbuilding/pdf/consultationhistoricp ps.pdf (accessed 28 April 2011)

Derycke, P.H. (1983), Economía y planificación urbana (IEAL), Madrid

De Souza Briggs, X. (1997), "Moving up versus moving out: Neighborhood effects in housing mobility programs", Housing Policy Debate, Vol. 8, No.1, pp.195-234.

English Heritage (2009), "Management of World Heritage Sites in England-English Heritage Guidance Note to Circular for England on the Protection of World Heritage 
Sites", London, available at: http://www.english -heritage .or.uk/publications/protection-management-of-world-heritage-sites- inengland/ehwhsplanningcircularguidance.pdf (accesed 28 April 2011)

Evans, G. and Shaw, S. (2001), "Urban Leisure and transport: regeneration effects" Journal of Leisure Property, Vol. 1(4), pp. 350-372.

Evans, G. (2005), "Measure for measure: evaluating the evidence of culture's contribution to regeneration", Urban Studies, Vol. 42(5/6), pp.959-984.

Fujita, M. (1986), "Optimal location of public facilities. Area dominance approach" Regional Science and Urban Economics, Vol. 16, pp. 241-268.

Glaeser, E.L. and Shapiro, J.M. (2003), "Urban Growth in the 1990s: Is the city living back?" Journal of Regional Science, Vol. 43, No.1, pp. 139-165.

Gónzalez-Páramo J.M. and Onrubia J. (1992), "El gasto público en vivienda en España" Hacienda Pública Española, Vol. 120/121, pp. 189-217.

Greffe, X. (2004), "Is heritage and asset or a liability?" Journal of Cultural Heritage, Vol.5, 3, pp.301-309.

Guellec, D. and Ralle, P. (1995), Les nouvelles théories de la croissance (La Decouverte), Paris

Ihlanfeldt, K.R. (2004), "Exclusionary land-use regulations within suburban communities: a review of the evidence and policy prescriptions", Urban Studies, Vol.41, No.2, pp. 261-283.

Jones C.E. and Slinn P. (2008), "Cultural Heritage in EIA - Reflections on Practice in North West Europe", Journal of Environmental Assessment Policy and Management, Vol. 10, Iss.3, pp.215-238.

Joseph, M.L., Chaskin, R.J. and Webber, H.S. (2007), "The theoretical basis for addressing poverty through mixed-income development", Urban Affairs Review, Vol. 42, No.3, pp. 369.

Krum, R. (1960), "Neighbourhood amenities: an economic analysis", Journal of Urban Economics, Vol.7, pp. 208-224.

Lawless, P. (2004), "Locating and explaining area-based urban initiatives: New Deal for Communities in England", Environment and Planning C: Government and Policy, Vol. 2, pp.383-399.

López García, M.A. (1992), "Algunos aspectos de la economía y la política de la vivienda", Investigaciones Económicas, Vol. 16 , No.1, pp. 3-41.

Lynch, A.K. and Rasmussen, D.W. (2001), "Is the cost of crime capitalized into house prices", Applied Economics, Vol. 33, No.15, pp. 1981-1989.

Manning, C. (1986), "Intercity differences in home price appreciation", Journal of Real Estate Research, Vol.1, pp. 46-66. 
McDonald, J.F. and McMillen, D.P. (2000), "Employment subcenters and subsequent real estate development in suburban Chicago", Journal of Urban Economics, Vol. 48, pp. 135-147.

McMillen, D.P. (2004), "Employment densities, spatial autocorrelation and subcenters in large urban areas", Journal of Regional Science, Vol. 44, pp. 225-243.

Murie, A. andRowlands, R. (2008), "The new politics of urban housing" Environment and Planning C: Government and Policy, Vol. 26, pp. 644-659.

Nijkamp, P. and Riganti, P. (2008), "Assessing cultural heritage benefits for urban sustainable development", International Journal of Services Technology and Management, Vol. 10, Iss.1, pp. 29-38.

Pereira Roders, A. and Van Oers, R. (2011) "World Heritage cities management", Facilities, Vol. 29 Iss: 7/8, pp.276- 285.

Richardson, H.W. (1977), "On the possibility of positive rent gradients", Journal of Urban Economics, Vol. 4, No.1, pp. 60-68.

Royuela, V., Lambiri, D. andBiagi, B. (2006) Economía urbana y calidad de vida. Una revisión del estado de conocimiento en España (Institut de Recerca en Economía Aplicada, Documents de Treball 2006/6), Barcelona

Royuela, V., Suriñach, J. and Artís, M. (2009), "La Influencia de la calidad de vida en el crecimiento urbano. El caso de la provincia de Barcelona", Investigaciones Regionales, Vol.13, pp. 57-84.

Sakashita, N. (1987), "Optimal location of public facilities under the influence of the land market", Journal of Regional Science, Vol. 27, pp. 1-12.

Schelling, T.C. (1969), "Models of Seggregation" American Economic Review, Papers and Proceedings, Vol. 59, pp. 488-493.

Schelling, T.C. (1971a), "On the Ecology of Micromotives", The Public Interest, Vol. 25, pp. 61-98

Schelling, T.C. (1971b), "Dynamic Models of Segregation" Journal of Mathematical Sociology, Vol. 1, No.2, pp. 143-186.

Schelling, T.C. (1972), "A process of Residential Segregation: Neighborhood Tipping". In A.H. Pascal (Ed.), Racial Discrimination in Economic Life (Lexington, MA: Lexington Books)

Scheling, T.C. (1978), Micromotives and Macrobehavior (Norton), New York

Stubbs, M. (2004), "Heritasestainability: Developing a Methodology for the Sustainable Appraisal of the Historic Environment", Planning, Practice \& Research, Vol. 19, (3), pp. 285-305. 
Tiebout, C. (1956), "A pure theory of local public expenditures", Journal of Political Economy, Vol. 64, pp. 416-424

Tweed, C. and Sutherland M. (2007), "Built Cultural heritage and sustainable urban development", Landscape and Urban Planning, Vol.83, No.1, pp. 62-69.

Van Oers, R., 2007, Towards new international guidelines for the conservation of historic urban landscapes (HUL)s, City \& Time, 3 (3): 3, pp. 43-51.

White, P. (1984), The West European City: A Social Geography (Longman), London 